\title{
Educación informal: la radio cultural en Aguascalientes Reseña del libro: Meza, Víctor; Historia al aire. La radio en Aguascalientes 1930-1980, UAA, México, 2016
}

\author{
Informal education: cultural radio in Aguascalientes. \\ Book Review: Meza, Víctor; Historia al aire. La radio en \\ Aguascalientes 1930-1980, UAA, México, 2016
}

Salvador Camacho Sandoval*

*Es profesor-investigador en la Universidad Autónoma de Aguascalientes (México), adscrito al Departamento de Educación, donde funge actualmente como líder del Cuerpo Académico consolidado "Instituciones y Actores de la Educación". Es miembro de la Sociedad Mexicana de Historia de la Educación (SOMEHIDE) y de la Latin American Studies Assosiation (LASA). Ha presentado ponencias y conferencias magistrales en encuentros y congresos a nivel nacional $e$ internacional. Entre sus más recientes publicaciones se encuentran los libros: La luz y el caracol. Estudio, lucha y placer en la universidad y La lechuza extraviada. Desencuentros: reformas y magisterio. Correo electrónico camacho sal@yahoo.com.mx

(D) https://orcid.org/0000-0001-8065-5530

\section{Historial editorial}

Recibido: 04-julio-2018

Primera revisión: 05-julio-2018

Segunda revisión: 03-octubre-2018

Aceptado: 05-octubre-2018

Publicado: 31-octubre-2018 
Educación informal: la radio cultural en Aguascalientes. Reseña del libro: Meza, Víctor; Historia al aire. La radio en Aguascalientes I930I980, UAA, México, 2016

La educación informal, como se sabe, es aquella que ofrece contenidos sin tener una planeación e intencionalidad clara; es la que forma hábitos y valores pero que no necesariamente tiene como propósito hacerlo; es más espontánea y muchas veces escapa a lineamientos de instituciones de Estado. Los clásicos ejemplos son la educación familiar y la que se da en los medios masivos de comunicación, como la prensa, la televisión y, de manera particular, la radio. De esta, podemos distinguir la radio comercial y la radio cultural, la cual generalmente no tiene finalidades lucrativas y cuenta con poca audiencia, aunque puede tener fines formativos $y$, por consiguiente, contenidos que pretenden orientar e influir en el desarrollo de la personalidad de la gente.

De la radio cultural trata el libro de Víctor Meza, quien estudió su doctorado en la Universidad de Zacatecas, atendió el caso de Aguascalientes, es originario de Jalisco y ahora esta reseña se publica en Chihuahua. Antes de presentar las ideas del libro, es pertinente señalar que Víctor Meza es una persona comprometida y apasionada con su trabajo en la radio desde I989. Según nos cuenta, desde pequeño le gustaba escuchar las transmisiones de la XEW de su tierra natal y la XELG de León, Guanajuato. Creció escuchando las radionovelas

214 clásicas de la W y las series producidas por Rafael Cutberto Navarro, entre ellas Kalimán, "El hombre increíble", la más famosa. Tampoco se podía perder Marcelino, pan y vino; aunque lo que más le gustaba eran los cuentos de Cri- Cri. Más grande, con su abuelo, Víctor se deleitaba escuchando música clásica y folclórica, jazz y blues. Con todo aquel 
ambiente de la llamada época romántica de la Radio, Víctor forjó una pasión e interés académico por la investigación en este campo.

Durante sus estudios de licenciatura, mientras algunos de sus compañeros exploraban en la diversidad de los medios de comunicación, Víctor profundizaba y hacía innovaciones en un pequeño cuarto de sonido, como operador de audio en XEUAA, y salía a la calle a pescar novedades para los programas radiofónicos. En su cabina de transmisión han pasado músicos, poetas, funcionarios públicos, políticos, candidatos a cargos locales y hasta candidatos a la presidencia de la República, como Cuauhtémoc Cárdenas Solórzano, y ha registrado cientos de casetes y otro tanto de cintas de entrevistas y programas realizados en Radio UAA. Además, recuperó de la basura, literalmente, documentos, revistas, guiones, fotografías, en fin, todo lo que tuviera que ver con la radiodifusión en la entidad.

Así, con una caja llena de documentos y una idea fija, llegó a la Unidad de Historia de la Universidad Autónoma de Zacatecas, para estudiar una maestría. Fue aceptado y años después se tituló con una historia de la radio, cuyo producto fue un documento que, con ciertas modificaciones, se ha convertido en libro.

Involucrado en el mundo de las artes y la academia, Víctor Manuel ha visto la actividad radiofónica con una perspectiva cultural y pedagógica, por lo que no son casualidades sus vínculos con el teatro popular, la recopilación de tradiciones orales populares, los proyectos de educación comunitaria en la región, la difusión de música de calidad para jóvenes y la realización de programas de rescate histórico. Él es de los que creen que los medios de comunicación son extraordinarios canales formativos al servicio de una sociedad en la que se dignifique a las personas con contenidos inteligentes. La radio, diremos ahora, sí educa y, si tenemos una visión de altura, educa bien. 
La radio es parte informativa, formativa y también recreativa, pues vinculados al sonido y a las palabras, la imaginación de quienes la escuchamos se agudiza al recibir música y escuchar historias. Allí se genera una comunicación en la que, a partir de una imagen auditiva, podemos "ver", como si percibiéramos el mar por el sonido que hacen las olas. Escuchamos e imaginamos, luego vemos. En definitiva, se trata de un "medio ciego" a la vez que un mundo a todo color. Bien lo dijo Marshall McLuhan, "la radio afecta a la gente de una forma muy íntima, de tú a tú, y ofrece todo un mundo de comunicación silenciosa entre el escritor-locutor y el oyente". Por todo esto Víctor Meza se aferró profesional y amorosamente a ella.

Otra aportación del libro es que nos señala la manera en que la radio se convirtió, gracias a su poder expansivo, en un instrumento político y de propaganda a favor de ciertos grupos y gobiernos. Desde su creación, se vinculó al poder y se utilizó para formar y orientar opiniones; tiene un carácter cultural y recreativo, pero también sociopolítico. Por lo mismo, el autor exploró la urdimbre del poder y el lugar que ha ocupado la radio en la confrontación de intereses políticos y económicos.

El libro nos muestra en un apartado breve el origen y desarrollo de la radio a finales del siglo XIX y principio del XX, destacando las primeras experiencias de este medio en México, con sus protagonistas y proyectos, para luego comentar los cimientos de la radiodifusión en Aguascalientes, con su tendencia a comercializar, informar, entretener y hacer política. Y es precisamente por estos intereses evidentes de lucro 216 y poder como Víctor Meza menciona que se margina el carácter cultural y formativo de la radio.

En el tema de la política, el libro analiza, por ejemplo, la manera en que el Partido Nacional Revolucionario, en el estado en los años treinta, vio en la radio un medio eficaz para cumplir con el propósito de unificar 
fuerzas políticas dispersas y cómo el gobernador Rafael Quevedo Morán, con fines de control, creó su propia emisora. En lo económico, en 1920 los dueños de los periódicos, que habían desdeñado el poder de la radio, siguieron trabajando despreocupados, pues les pareció un artefacto poco peligroso para sus negocios. Estaban muy equivocados, y no tardaron en usarla para su beneficio.

Víctor Manuel investiga también el origen y los factores que influyeron en el desarrollo de la radio comercial en la entidad en la segunda mitad de la década de los años treinta. El nombre de Pedro Rivas es clave como impulsor de nuevas emisoras, su influencia trastocó el mundo de la radio en el estado y trascendió a otros, en un remolino de innovación tecnológica, ímpetu comercial e iniciativas recreativas y musicales. Fue en estas emisoras comerciales donde se dio cabida al atractivo mundo del Teatro Estudio, las cuales convocaban y ofrecían oportunidades de éxito y fama a los artistas aficionados.

Más tarde, lo documenta el libro, desde el gobierno apareció XENM Radio Casa de la Cultura, que, a falta de presupuesto, aprovechaba y reciclaba las grabaciones regaladas por embajadas de distintos países, las cuales contenían programas culturales y música que rara vez se escuchaba en Aguascalientes. El autor nos comparte también su malestar porque la estación dejó el proyecto cultural y se transformó en la voz propagandística del gobernador del estado.

En este libro podemos conocer, además, otra experiencia radiofónica singular y no comercial: la estación establecida por una orden religiosa (Agustinos), XHMR Estéreo Mendel, la cual sigue operando desde la segunda mitad de los años setenta en frecuencia modulada y emite una programación musical interrumpida por pequeñas sentencias religiosas, principalmente de San Agustín, con el propósito de generar una reflexión educativa y moral entre los radioescuchas. Al igual que la 
mayoría de las estaciones permisionarias en el país, Estéreo Mendel lucha por sobrevivir.

Víctor Manuel pone atención especial en la radio de la Universidad Autónoma de Aguascalientes, reivindicándola como la única estación que presenta una programación ajena a intereses comerciales y políticos que tienen otras estaciones, sin negar que falta un análisis más detallado de una presunta neutralidad, pues, por ejemplo, en aras de propiciar la crítica y favorecer la democracia en épocas electorales, la balanza en ocasiones tiende a dejar su equilibrio. Con todo, es la única alternativa que ha existido en la entidad para abrir puertas y encender micrófonos al debate sobre asuntos de relevancia social y para ofrecer al público exigente un espectro musical que casi no se escucha en la radio comercial. En cierta medida, cumple con su propósito de generar opinión crítica y favorecer una alternativa cultural en la que el desarrollo de la sensibilidad y el pensamiento creativo de los radioescuchas es una prioridad.

Este libro está elaborado con fuentes ricas y diversas, desde la consulta y análisis documental tradicional hasta documentos auditivos, fotográficos y videos sobre la radio. También usó la historia oral, como un medio extraordinario para reconstruir ese pasado vivo que sigue interactuando en el presente. Estas fuentes primarias se complementaron con libros y artículos de revistas, así como con la experiencia de años que tiene el autor en la radio cultural. Finalmente, en la investigación de temas como este, la subjetividad aparece

218 inevitable y hay que aprovecharla, sin el prurito positivista de que "no se puede, ni se vale".

Víctor Manuel ha escrito una historia de la radio y sigue guardando otras tantas en espera de que algún día sean parte de estas historias al aire. Sabe que en el abanico de estaciones y en el mundo radiofónico se 
expresa lo que la sociedad tiene y carece y lo que a la gente le preocupa y le apasiona. Del poder que tiene la radio es posible vislumbrar la confrontación de ideas e intereses, a la vez que es posible convertir el medio en un instrumento abierto y liberador, que cuestione el status quo y propicie la imaginación y el arribo a mejores mundos posibles.

Este artículo se publica bajo una licencia de Creative Commons Reconocimiento-NoComercial 4.0 Internacional, y puede ser usados gratuitamente para fines no comerciales, dando los créditos a los autores y a la revista.

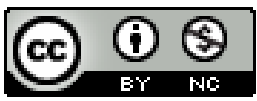

